OPEN ACCESS

Edited by:

Detlev Boison,

Legacy Health, USA

Reviewed by:

John J. Woodward, Medical University of South Carolina,

USA

Masahito Kawamura Jikei University School of Medicine,

Japan

*Correspondence:

Qi Wan

qwanwh@hotmail.com

${ }^{\dagger}$ These authors have contributed equally to this work.

Received: 18 July 2016 Accepted: 29 September 2016 Published: 19 October 2016

Citation:

Li L-J, Hu R, Lujan B, Chen J,

Zhang J-J, Nakano Y, Cui T-Y, Liao M-X, Chen J-C, Man H-Y, Feng H and Wan Q (2016) Glycine Potentiates

AMPA Receptor Function through Metabotropic Activation of GluN2A-Containing NMDA Receptors. Front. Mol. Neurosci. 9:102. doi: 10.3389/fnmol.2016.00102

\section{Glycine Potentiates AMPA Receptor Function through Metabotropic Activation of GluN2A-Containing NMDA Receptors}

\author{
Li-Jun $\mathrm{Li}^{1+}$, Rong $\mathrm{Hu}^{2,3+}$, Brendan Lujan ${ }^{2}$, Juan Chen ${ }^{4}$, Jian-Jian Zhang ${ }^{5}$, \\ Yasuko Nakano ${ }^{2}$, Tian-Yuan Cui ${ }^{2}$, Ming-Xia Liao ${ }^{2}$, Jin-Cao Chen ${ }^{5}$, Heng-Ye Man ${ }^{6}$, \\ Hua Feng ${ }^{3}$ and Qi Wan ${ }^{1,2,5,7 *}$ \\ ${ }^{1}$ Department of Physiology, Toronto Western Research Institute, School of Medicine, University of Toronto, Toronto, Canada, \\ ${ }^{2}$ Department of Physiology and Cell Biology, University of Nevada School of Medicine, Reno, NV, USA, ${ }^{3}$ Department of \\ Neurosurgery, Southwest Hospital, Chongqing, China, ${ }^{4}$ Department of Neurology, Central Hospital of Wuhan, Wuhan, China, \\ ${ }^{5}$ Department of Neurosurgery, Zhongnan Hospital, Wuhan University School of Medicine, Wuhan, China, ${ }^{6}$ Department of \\ Biology, Boston University, Boston, MA, USA, ' Department of Physiology, School of Basic Medical Sciences, Wuhan \\ University School of Medicine, Wuhan, China
}

NMDA receptors are $\mathrm{Ca}^{2+}$-permeable ion channels. The activation of NMDA receptors requires agonist glutamate and co-agonist glycine. Recent evidence indicates that NMDA receptor also has metabotropic function. Here we report that in cultured mouse hippocampal neurons, glycine increases AMPA receptor-mediated currents independent of the channel activity of NMDA receptors and the activation of glycine receptors. The potentiation of AMPA receptor function by glycine is antagonized by the inhibition of ERK1/2. In the hippocampal neurons and in the HEK293 cells transfected with different combinations of NMDA receptors, glycine preferentially acts on GluN2A-containing NMDA receptors (GluN2ARs), but not GluN2B-containing NMDA receptors (GluN2BRs), to enhance ERK1/2 phosphorylation independent of the channel activity of GluN2ARs. Without requiring the channel activity of GluN2ARs, glycine increases AMPA receptor-mediated currents through GluN2ARs. Thus, these results reveal a metabotropic function of GluN2ARs in mediating glycine-induced potentiation of AMPA receptor function via ERK1/2 activation.

Keywords: glycine, AMPA receptor, NMDA receptor, ERK1/2, hippocampal neurons, HEK293 cells

\section{INTRODUCTION}

NMDA receptors (NMDARs) are ligand-gated $\mathrm{Ca}^{2+}$-permeable channels that consist of GluN1, GluN2 (GluN2A-GluN2D), and GluN3 (GluN3A-GluN3B) subunits (Monyer et al., 1992). The GluN2A subunit-and GluN2B subunit-containing NMDARs (GluN2ARs and GluN2BRs, respectively) are the major subtypes of NMDARs expressed in the mammalian CNS (Dingledine et al., 1999). NMDARs mediate excitatory neurotransmission (Dingledine et al., 1999), which play essential roles in synaptic plasticity (Malenka and Nicoll, 1999; Barria and Malinow, 2002), neural development (Constantine-Paton et al., 1990; Kerchner and Nicoll, 2008) and glutamate-induced neurotoxicity (Choi, 1988; Aarts et al., 2002; Tu et al., 2010). The agonist glutamate binding to GluN2 subunits and co-agonist glycine binding to GluN1 subunits are required to activate the 
channel activity of NMDARs (Johnson and Ascher, 1987). Different GluN2 subunits confer distinct roles of NMDAR subtypes (Loftis and Janowsky, 2003; Kim M. J. et al., 2005; Hayashi et al., 2009). Activation of NMDARs has been shown to regulate the function of AMPA receptors (AMPARs) (Kim M. J. et al., 2005), which is considered to be a postsynaptic mechanism for the regulation of synaptic plasticity including calciumdependent long-term potentiation (Malinow and Malenka, 2002; Collingridge et al., 2004; Li et al., 2010; Man, 2011; Lu and Roche, 2012).

While the ionotropic function of NMDARs has been well studied, recent studies suggest that NMDAR has a metabotropic property (Vissel et al., 2001; Kessels et al., 2013; Nabavi et al., 2013; Tamburri et al., 2013; Birnbaum et al., 2015; Stein et al., 2015; Weilinger et al., 2016). It is reported that ligand binding to NMDARs is sufficient to induce long-term depression (LTD); but does not require ion flow through NMDARs (Nabavi et al., 2013). NMDA-receptor activation but not ion flux is required for amyloid-beta induced synaptic depression (Tamburri et al., 2013) and a metabotropic activity of GluN2BRs mediates $\beta$ amyloid-induced synaptic depression (Kessels et al., 2013). The metabotropic activity of NMDARs is also found to mediate Abeta oligomer-induced synaptic loss (Birnbaum et al., 2015), couple Src family kinases to pannexin-1 in excitotoxic injury (Weilinger et al., 2016) and drive activity-induced dendritic spine shrinkage (Stein et al., 2015). In the present study we reveal a metabotropic activity of GluN2AR that mediates glycine-induced potentiation of AMPAR function through activation of extracellular signalregulated kinase $1 / 2(\mathrm{ERK} 1 / 2)$.

\section{MATERIALS AND METHODS}

\section{Hippocampal Neuronal Culture}

The hippocampal neuronal cultures were prepared from C57BL/6 mice at gestation day 17 using a modified protocol (Brewer et al., 1993; Shan et al., 2009). C57BL/6 mice were obtained from both Toronto Western Research Institute (TWRI), University of Nevada School of Medicine (UNSM) and Wuhan University School of Medicine (WUSM). Briefly, dissociated neurons were suspended in plating medium (Neurobasal medium, 2\% B-27 supplement, 10\% FBS, $0.5 \mu \mathrm{M}$ L-glutamine, and $25 \mu \mathrm{M}$ glutamic acid) and plated on poly-D-lysine coated Petri dishes. After 3 days in culture, half of the plating medium was removed and replaced with maintenance medium (Neurobasal medium, 2\% B-27 supplement, and $0.5 \mu \mathrm{M} \mathrm{L-}$ glutamine). Thereafter, maintenance medium was changed in the same manner every 3 days. The cultured neurons were used for all the experiments at 12-14 days after plating. All animal work was conducted according to the guidelines set forth by TWRI Canadian Council on Animal Care Committee (CCACC), the UNSM and WUSM Institutional Animal Care and Use Committee (IACUC). All procedures were approved by the TWRI-CCACC, the UNSM-IACUC and WUSM - IACUC.

\section{Electrophysiological Recordings}

For the recording of AMPA-induced whole-cell currents, the recording electrode resistance was $2-5 \mathrm{M}^{\prime} \Omega$ when filled with a standard intracellular solution containing $140 \mathrm{mM} \mathrm{CsCl,} 2 \mathrm{mM}$ $\mathrm{MgCl}_{2}, 1 \mathrm{mM} \mathrm{CaCl}$, $5 \mathrm{mM}$ EGTA, $10 \mathrm{mM} \mathrm{HEPES,} 4 \mathrm{mM}$ $\mathrm{K}_{2} \mathrm{ATP}$, titrated to $\mathrm{pH} 7.3$ with $\mathrm{CsOH}$ and the osmolality was 300-315 mOsm. Liquid junction potential of $4.8 \mathrm{mV}$ was not corrected. The cultures were bathed in the ECS-1 (10 $\mu \mathrm{M}$ MK-801, 5.0 mM EGTA, $5 \mu \mathrm{M}$ strychnine, $0.5 \mu \mathrm{M}$ TTX, $137 \mathrm{mM} \mathrm{NaCl}, 5.4 \mathrm{mM} \mathrm{KCl}, 1.0 \mathrm{mM} \mathrm{MgCl}_{2}, 25 \mathrm{mM}$ HEPES, $33 \mathrm{mM}$ Glucose, titrated to $\mathrm{pH} 7.4$ with osmolarity of 300$320 \mathrm{mOsm})$. Neurons were held at $-70 \mathrm{mV}$ under voltageclamp. AMPAR-mediated whole-cell currents were evoked by pressure application (22 psi, $100 \mathrm{~ms}$; PDES-2L, npi Electronic $\mathrm{GmbH}$, Germany) of AMPA $(100 \mu \mathrm{M})$ from a micropipette with its tip located $\sim 20 \mu \mathrm{m}$ from the recorded cell. For the recording of NMDA receptor-mediated whole-cell currents, the recording electrode resistance was $2-5 \mathrm{M}^{\prime} \Omega$ when filled with a standard intracellular solution. Same bath solution was used without including MK-801. Neurons were held at $+40 \mathrm{mV}$ under voltage-clamp. NMDA receptor-mediated whole-cell currents were recorded by pressure application of NMDAR agonist aspartate $(100 \mu \mathrm{M})$ and glycine $(1.0 \mu \mathrm{M} ; 22 \mathrm{psi}, 100 \mathrm{~ms})$ from a micropipette with its tip located $\sim 20 \mu \mathrm{m}$ from the recorded cell. Drugs were delivered at intervals of $60 \mathrm{~s}$. Data were acquired with an Axopatch 200B amplifier and pClamp 10 software interfaced to a Digidata 1322A acquisition board (Molecular Devices, CA), and signals were filtered at $2 \mathrm{kHz}$ and digitized at $10 \mathrm{kHz}$.

Recording of miniature EPSCs (mEPSCs) was performed as described previously (Liu et al., 2006). The cultures were bathed in the ECS-1 containing $10 \mu \mathrm{M}$ bicuculline for the recording of AMPAR mEPSCs. At least 200 individual AMPAR mEPSCs were collected before and after application of glycine $(100 \mu \mathrm{M})$. Records were filtered at $2 \mathrm{kHz}$ and analyzed with a Clampfit 10.3 program (Molecular Devices). The other experimental conditions and methods were same as those of recording for AMPAR-mediated whole-cell currents.

AMPAR-mediated fEPSPs were recorded in the hemibrain slices $(400 \mu \mathrm{m})$ containing hippocampus prepared by a vibratome (Leica VT 1200s) using C57BL/6 mice (age of $3 \sim 8$ weeks). Before decapitation, mice were anesthetized and underwent trans-cardiac infusion with a cold choline chloride solution containing (in $\mathrm{mM}$ ): $50 \mathrm{NaCl}, 80$ choline chloride, $3.5 \mathrm{KCl}, 7 \mathrm{MgCl}_{2}, 0.5 \mathrm{CaCl}_{2}, 2 \mathrm{NaH}_{2} \mathrm{PO}_{4}, 5 \mathrm{HEPES}$ and 20 glucose. Slices were stabilized in oxygenated $\left(95 \% \mathrm{O}_{2}\right.$ and $5 \%$ $\mathrm{CO}_{2}$ ) artificial cerebrospinal fluid (aCSF) containing (in $\mathrm{mM}$ ): $125 \mathrm{NaCl}, 3.5 \mathrm{KCl}, 1.25 \mathrm{NaH}_{2} \mathrm{PO}_{4}, 25 \mathrm{NaHCO}_{3}, 2 \mathrm{CaCl}_{2}, 1.3$ $\mathrm{MgCl}_{2}, 10$ glucose and 2 kynurenic acid $(\mathrm{pH} 7.4$ when aerated with $95 \% \mathrm{O}_{2}$ and $5 \% \mathrm{CO}_{2}$ ) at $35^{\circ} \mathrm{C}$ for $30 \mathrm{~min}$. The slices were then recovered in a modified aCSF (aCSF-1) containing 10 $\mu \mathrm{M}$ bicuculline, $10 \mu \mathrm{M} \mathrm{MK}-801$ and $5 \mu \mathrm{M}$ strychnine but no kynurenic acid at room temperature for over $2 \mathrm{~h}$. All recordings were performed by perfusing the slices $(10-15 \mathrm{ml} / \mathrm{min})$ at room temperature with aCSF-1 that was saturated with $95 \% \mathrm{O}_{2}$ and $5 \% \mathrm{CO}_{2}$ (Wu et al., 2005). Extracellular recording electrodes (1 2 $\mathrm{M} \Omega$ ) filled with aCSF were used for the recording. The recording electrode was placed in the CA1 apical dendritic layer. Local afferent stimulation was conducted via placing a bipolar tungsten wire electrode (tip diameter of $50 \mu \mathrm{m}$ ) in 
CA3 stratum radiatum. Constant current pulses of $0.1 \mathrm{~ms}$ were generated by a Grass stimulator (Grass Technologies, West Warwick, RI) and delivered through an isolation unit every $30 \mathrm{~s}$. After stable baseline recordings of fEPSPs over $10 \mathrm{~min}$ in the slices perfused with aCSF-1, the slices were perfused with aCSF-1 containing $1 \mathrm{mM}$ glycine for $10 \mathrm{~min}$, and then perfused with the aCSF-1 alone for over $30 \mathrm{~min}$. MultiClamp 700B (Molecular Devices) was used for the recording. Data acquisition and analysis were performed using DigiData 1322A (Molecular Devices) and the analysis software pClamp 10 (Molecular Devices). Signals were filtered at $2 \mathrm{kHz}$ and sampled at $10 \mathrm{kHz}$.

\section{Transfections and shRNA Lentiviral Particles Treatment}

The control shRNAs, GluN2A shRNAs or GluN2B shRNAs were transfected in cultured hippocampal neurons and the cDNAs of GFP, GluN1, GluN2A, GluN2B GluNR1(N598Q) were transfected in cultured HEK293 cells. Transfections were performed using Lipofectamine 2000 (Invitrogen) as previously described (Wan et al., 1997; Ning et al., 2004).

GluN2A and GluN2B shRNA lentiviral particles were purchased from GeneChem (China). The transduction of lentiviral particles was performed in cultured cortical neurons based on the manufacturer's instructions.

\section{Western Blotting}

Western blotting assay was performed as described previously (Liu et al., 2006). Antibodies against phospho-ERK1/2 (Thr202/Tyr204) (Cell Signaling Technology, Beverly, MA) and total ERK1/2 (Cell Signaling Technology) were used. For the detection of phospho-ERK1/2, samples prepared in the same day were freshly used for the Western blotting assay for all the experiments. Primary antibodies were labeled with horseradish peroxidase-conjugated secondary antibody. The phospho-ERK1/2 protein bands were imaged using SuperSignal West Femto Maximum Sensitivity Substrate (Pierce, Rockford, IL, USA). For the detection of total ERK1/2, the same polyvinylidene difluoride membrane was stripped and then reprobed with primary antibody against total ERK1/2 (Cell Signaling Technology). The ERK1/2 protein bands were imaged using Pierce ECL Western Blotting Substrate (Pierce). The EC3 Imaging System (UVP, LLC, Upland, CA) was used to obtain Western blot images directly from polyvinylidene difluoride membranes. The quantification of Western blots was performed using Image J software as previously described (Ning et al., 2004; Liu et al., 2006).

\section{Statistics}

All population data were expressed as mean \pm s.e. Student's $t$ test or ANOVA test was used where appropriate to examine the statistical significance of the differences between groups of data. Newman-Keuls tests were used for post-hoc comparisons when appropriate. Significance was placed at $p<0.05$.

\section{RESULTS}

\section{Glycine Potentiates AMPA-Induced Whole-Cell Currents Independent of NMDAR Channel Activity}

To determine whether AMPAR function is regulated by a metabotropic activity of NMDARs, we measured the effect of NMDAR co-agonist glycine on AMPAR function in cultured mouse hippocampal neurons in which the channel activity of NMDARs was inhibited by a $\mathrm{Ca}^{2+}$-free extracellular solution (ECS) in which $\mathrm{Ca}^{2+}$ was not included but with the addition of MK-801 $(10 \mu \mathrm{M})$, EGTA $(5.0 \mathrm{mM})$ and strychnine $(10 \mu \mathrm{M})$. This $\mathrm{Ca}^{2+}$-free ECS with the inclusion of MK-801 (a noncompetitive antagonist preventing the flow of ions through the NMDAR channels) (MacDonald and Nowak, 1990; Rosenmund et al., 1993) and the $\mathrm{Ca}^{2+}$ chelator EGTA ensured that no $\mathrm{Ca}^{2+}$ passed through NMDAR channels, The glycine receptor antagonist strychnine was included in the $\mathrm{Ca}^{2+}$-free ECS to exclude the possible effects mediated by glycine activation of glycine receptors (Lynch, 2004). We named this specific solution as ECS-1 (10 $\mu \mathrm{M}$ MK-801, 5.0 mM EGTA, $10 \mu \mathrm{M}$ strychnine, 0.5 $\mu \mathrm{M}$ TTX, $137 \mathrm{mM} \mathrm{NaCl}, 5.4 \mathrm{mM} \mathrm{KCl}, 1.0 \mathrm{mM} \mathrm{MgCl} 2,25 \mathrm{mM}$ HEPES, $33 \mathrm{mM}$ Glucose, titrated to $\mathrm{pH} 7.4$ with osmolarity of 300-320 mOsm). The cultured neurons were treated with ECS1 for 10 min to suppress the channel activity of NMDARs. This treatment will be referred to as the NMDAR channel inactivation procedure.

Prior to recording of AMPA-induced whole-cell currents, the neuronal cultures were subjected to the NMDAR channel inactivation procedure. AMPAR currents were recorded in ECS-1 with the holding potential at $-70 \mathrm{mV}$. Following a stable recording of AMPAR currents, glycine $(100 \mu \mathrm{M})$ was continuously puffed onto the recorded neuron for $1.0 \mathrm{~min}$. We found that the AMPAR peak currents were significantly increased after the treatment of glycine in a dose-dependent manner and the currents were inhibited by specific AMPAR antagonist CNQX (Figures 1A,B). To verify whether the observed effect of glycine on AMPAR peak currents was under the conditions where the activity of NMDAR channels was inhibited by the NMDAR channel inactivation procedure, we measured NMDAinduced currents and showed that the currents were not evoked in neurons subjected to NMDAR channel inactivation procedure (Figure 1C).

To determine whether the observed effect of glycine on AMPAR currents occurred at physiologically relevant levels of extracellular $\mathrm{Ca}^{2+}$, we treated the neurons with standard ECS $(137 \mathrm{mM} \mathrm{NaCl}, 2.0 \mathrm{mM} \mathrm{CaCl}, 5.4 \mathrm{mM} \mathrm{KCl}, 1.0 \mathrm{mM}$ $\mathrm{MgCl}_{2}, 25 \mathrm{mM}$ HEPES, $33 \mathrm{mM}$ Glucose, titrated to $\mathrm{pH} 7.4$ with osmolarity of 300-320 mOsm) containing $10 \mu \mathrm{M}$ MK-801, 10 $\mu \mathrm{M}$ strychnine and $0.5 \mu \mathrm{M}$ TTX for $10 \mathrm{~min}$. We then recorded AMPA-induced whole-cell currents and treated the neurons with glycine $(100 \mu \mathrm{M})$. As shown in Figure 1D, glycine treatment for 1.0 min increased AMPAR peak currents in the hippocampal neurons in which NMDAR channels were blocked by MK- 801 .

Endogenous $\mathrm{Mg}^{2+}$ blocks NMDAR channels while AMPAR whole-cell currents were recorded at the holding potential of $-70 \mathrm{mV}$ (Kuner and Schoepfer, 1996). To test the glycine effect 


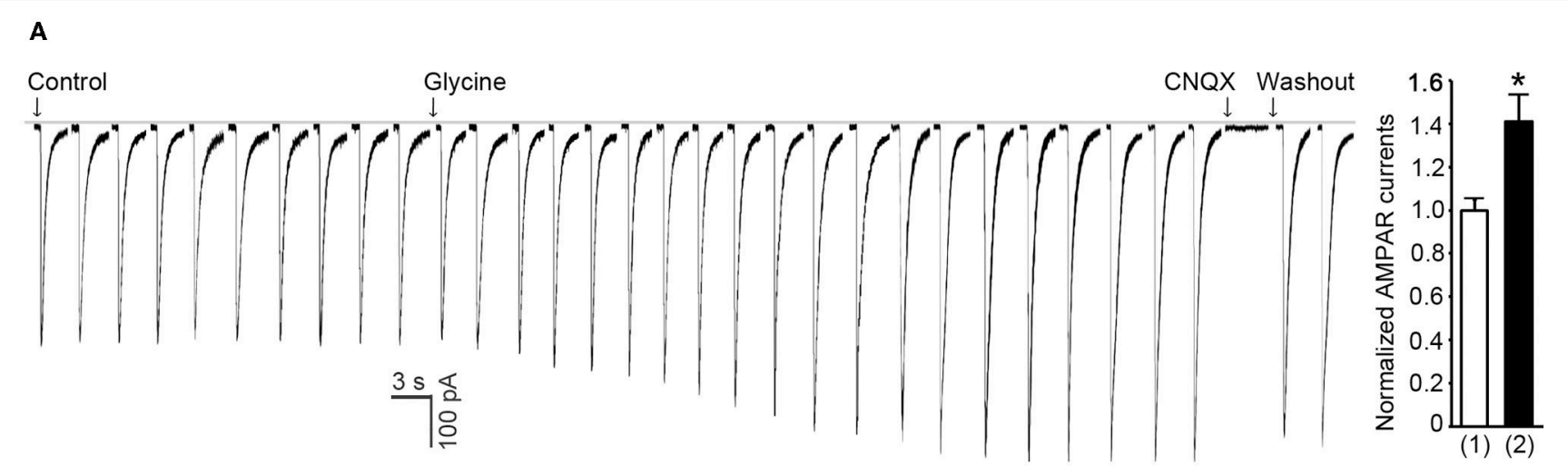

B

C

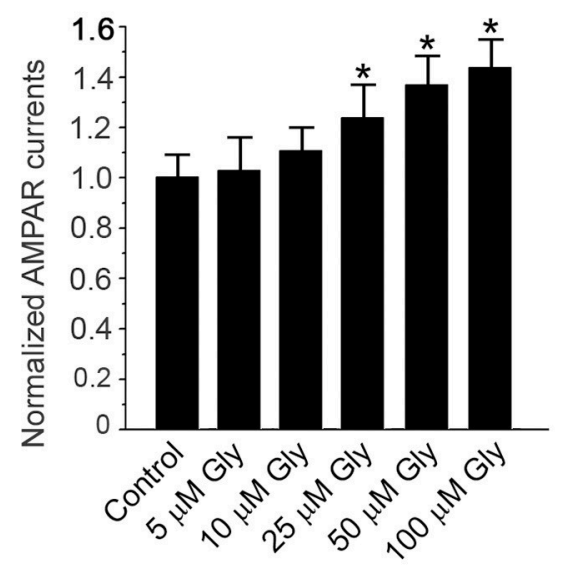

NMDAR-mediated whole-cell currents

D

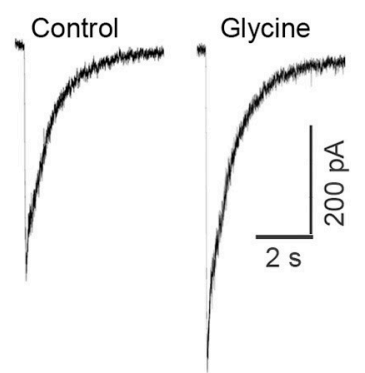

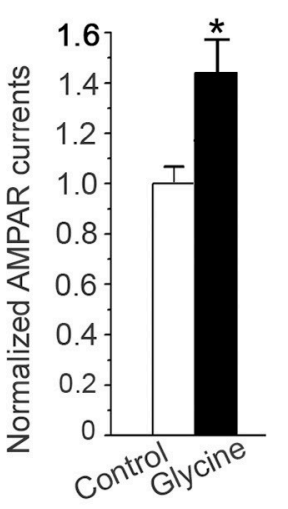

E
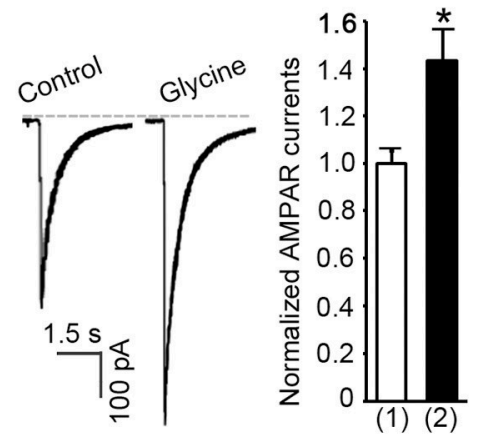

FIGURE 1 | Glycine enhances AMPAR-mediated whole-cell currents in hippocampal neurons in which the NMDAR channel activity and glycine receptor activation are inhibited. (A) AMPA (100 $\mu \mathrm{M})$-induced whole-cell currents are increased by 1.0 min treatment of $100 \mu \mathrm{M}$ glycine in hippocampal neurons after NMDARs and glycine receptors are inhibited ( $\left.n=15,{ }^{*} p<0.05\right)$. The current is reversibly blocked by AMPAR antagonist CNQX (20 $\mu$ M). (1) Control; (2) Glycine treatment. (B) The dose-dependent effect of glycine on AMPAR currents $\left(n=11,{ }^{*} p<0.05\right)$. (C) Sample recordings showing that NMDA-induced whole-cell current cannot be induced in neurons where NMDAR channels are blocked by MK-801 using our NMDAR blockade procedure. (D) At normal levels of extracellular Ca $2+$, glycine $(100 \mu \mathrm{M})$ increases AMPAR currents independent of the channel activity of NMDARs and the activation of glycine receptors $\left(n=6\right.$, $\left.{ }^{\star} p<0.05\right)$. (E) Without treatment with MK-801, AMPAR peak currents are increased by glycine (100 $\mu \mathrm{M})$ treatment under the holding potential of -70 mV with which the NMDAR channels are blocked by $\mathrm{Mg}^{2+}\left(n=7,{ }^{*} p<0.05\right)$. (1) Control; (2) Glycine.

in a physiologically relevant condition in which NMDARs are not blocked by the external application of ECS-1, we measured AMPAR currents in neurons treated with standard ECS only containing $10 \mu \mathrm{M}$ strychnine and $0.5 \mu \mathrm{M}$ TTX. We showed that without use of ECS-1, glycine treatment $(100 \mu \mathrm{M})$ for $1.0 \mathrm{~min}$ increased AMPAR peak currents with the holding potential at 
$-70 \mathrm{mV}$ (Figure 1E). Together, these results indicate that glycine potentiates AMPAR function independent of the channel activity of NMDARs.

\section{Glycine Enhances AMPAR-Mediated Synaptic Function Independent of NMDAR Channel Activity}

As the observed enhancement of AMPAR-mediated wholecell currents might represent an upregulation of synaptic responses of AMPARs to glycine, we tested the effect of glycine on AMPAR-mediated miniature excitatory postsynaptic currents (mEPSCs). NMDAR channels in the hippocampal neurons were blocked by the NMDAR channel inactivation procedure as described above, and the neurons were bathed in the ECS-1 containing $10 \mu \mathrm{M} \mathrm{GABA}_{\mathrm{A}}$ receptor antagonist bicuculline for the entire recording period. Our data showed that AMPAR-mediated mEPSCs were significantly increased in neurons following $1.0 \mathrm{~min}$ treatment of glycine $(100 \mu \mathrm{M})$, and this enhancement lasted for $\sim 30 \mathrm{~min}$ (Figure 2A). Glycine application increased both amplitude and frequency of AMPAR mEPSCs (Figures $2 \mathrm{~A}-\mathrm{C}$ ), suggesting that while glycine enhances postsynaptic AMPAR function in a NMDAR channel activityindependent manner, a presynaptic modification is also induced by glycine.

To validate the observed effect of glycine on synaptic AMPAR function in more physiologically relevant conditions, we recorded field excitatory post-synaptic potentials (fEPSP) in adult mouse hippocampal slices. AMPAR-mediated fEPSPs were pharmacologically isolated by treating the slices with $\mathrm{GABA}_{\mathrm{A}}$ receptor antagonist bicuculline $(10 \mu \mathrm{M})$ and NMDAR blocker MK-801 $(10 \mu \mathrm{M})$. As described in the section of Methods, the NMDAR channels in hippocampal slices were blocked by a NMDAR channel inactivation procedure that was similar to that in hippocampal neuronal cultures. After stable baseline recordings of AMPAR-mediated fEPSPs for over $10 \mathrm{~min}$, treatment of $1.0 \mathrm{mM}$ glycine for $10 \mathrm{~min}$ led to an increased amplitude of AMPAR-mediated fEPSP in the hippocampus (Figure 2D).

\section{Potentiation of AMPAR Function by Glycine Requires ERK1/2 Activation}

Because ERK1/2 is involved in mediating AMPAR-mediated synaptic plasticity (Kim M. J. et al., 2005), we tested the effect of ERK1/2 inhibition on the upregulation of AMPAR function by glycine (Hotokezaka et al., 2002). The channels of NMDARs in hippocampal neurons were blocked by the NMDAR channel inactivation procedure, and the hippocampal neurons were bathed in ECS-1 containing ERK1/2 inhibitor U0126 for the recordings of both AMPAR-mediated mEPSCs and AMPAinduced whole-cell currents. We found that U0126 treatment for the entire recording period significantly reduced the upregulation of both AMPAR mEPSC and AMPA-induced whole-cell currents by glycine (100 $\mu \mathrm{M} ; 1.0 \mathrm{~min}$ ) (Figures $3 \mathrm{~A}-\mathrm{E}$ ), suggesting that ERK1/2 activation mediates glycine-induced potentiation of AMPAR function.

\section{Glycine Promotes ERK1/2 Activation Independent of NMDAR Channel Activity}

The electrophysiological results (Figures 1-3) led us to reason that glycine might activate a metabotropic function of NMDARs to enhance ERK1/2 activation that in turn lead to the enhancement of AMPAR function. To test this possibility, we performed western blot assay to test the effect of glycine on ERK1/2 activation by measuring the phosphorylation level of ERK1/2 in cultured hippocampal neurons. The levels of ERK1/2 phosphorylation (p-ERK1/2) on Thr202/Tyr204 were quantified by calculating the ratio of p-ERK1/2 to total ERK1/2 (tERK1/2). After NMDARs were blocked by the NMDAR channel inactivation procedure, the cultures were treated with ECS-1 containing glycine $(100 \mu \mathrm{M})$ for $1.0 \mathrm{~min}$ and then washed with ECS-1 for $30 \mathrm{~min}$. The neurons were then collected for western blot assay. As shown in Figure 4A, glycine increased ERK1/2 phosphorylation in hippocampal neurons where the NMDAR channel activity and glycine receptors were inhibited, and the glycine effect was dose-dependent (Figure 4B). In the same experimental conditions, hippocampal neurons were treated with ECS- 1 containing $5.0 \mathrm{mM}$ BAPTA, a $\mathrm{Ca}^{2+}$ chelator that has faster calcium-binding kinetics than EGTA (Adler et al., 1991). We found that BAPTA treatment did not interfere with glycine elevation of ERK1/2 phosphorylation (Figure 4C). As BAPTA chelates the possible residual $\mathrm{Ca}^{2+}$ in the ECS-1, this result provides further evidence suggesting that the effect of glycine on ERK1/2 phosphorylation is independent of extracellular $\mathrm{Ca}^{2+}$.

To determine whether the observed effect of glycine on ERK1/2 phosphorylation occurred at physiologically relevant levels of extracellular $\mathrm{Ca}^{2+}$, we treated the neurons with standard ECS containing $10 \mu \mathrm{M}$ MK-801, $10 \mu \mathrm{M}$ strychnine and $0.5 \mu \mathrm{M}$ TTX for $10 \mathrm{~min}$. The neurons were treated with standard ECS containing $100 \mu \mathrm{M}$ glycine, $10 \mu \mathrm{M}$ MK-801, $10 \mu \mathrm{M}$ strychnine and $0.5 \mu \mathrm{M}$ TTX for $1.0 \mathrm{~min}$ and then washed with standard ECS containing $10 \mu \mathrm{M}$ MK-801, $10 \mu \mathrm{M}$ strychnine and $0.5 \mu \mathrm{M}$ TTX. We found that at $30 \mathrm{~min}$ after the treatment of $100 \mu \mathrm{M}$ glycine, the levels of ERK1/2 phosphorylation were elevated (Figure 4D).

\section{Glycine Enhances ERK1/2 Activation through a Metabotropic Activity of GluN2ARs}

In order to obtain direct evidence to determine whether a metabotropic NMDAR mediated glycine potentiation of ERK1/2 activation, we tested the effects of glycine on ERK1/2 phosphorylation in HEK293 cells transiently expressed NMDARs. The cDNAs of GluN1, GluN2A and/or GluN2B subunits were transfected in various combinations into the HEK293 cells (Wan et al., 1997). Prior to the treatment of glycine $(100 \mu \mathrm{M})$, the transfected cells were subjected to the NMDAR channel inactivation procedure. ERK1/2 phosphorylation was measured in the transfected cells at $30 \mathrm{~min}$ after $1.0 \mathrm{~min}$ treatment of glycine $(100 \mu \mathrm{M})$ as described above (Figure 4A). We found that glycine had no effect on ERK1/2 phosphorylation in non-transfected HEK293 cells (Figure 5A). However, glycine increased ERK1/2 phosphorylation in HEK293 cells transfected with cDNAs 
A

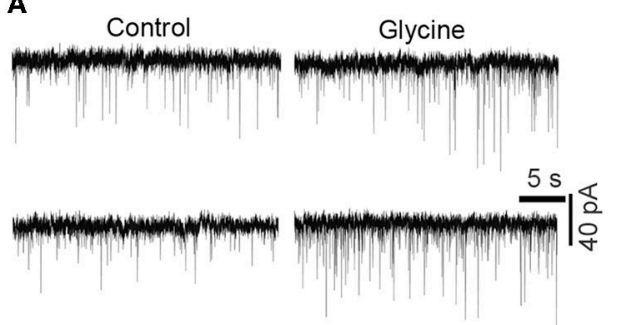

Haw

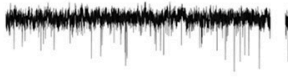

B

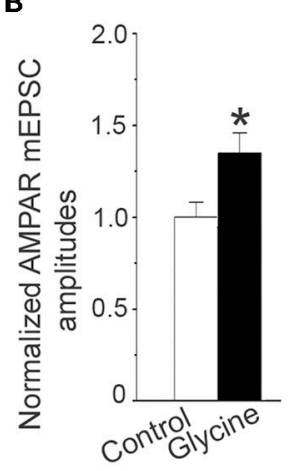

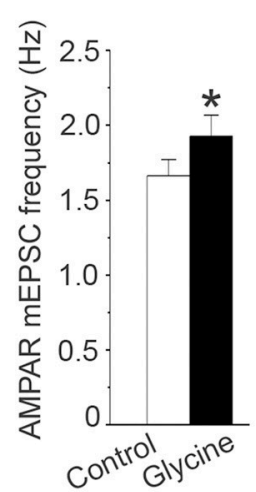

C

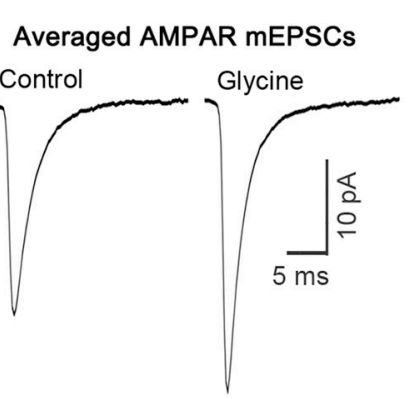

D

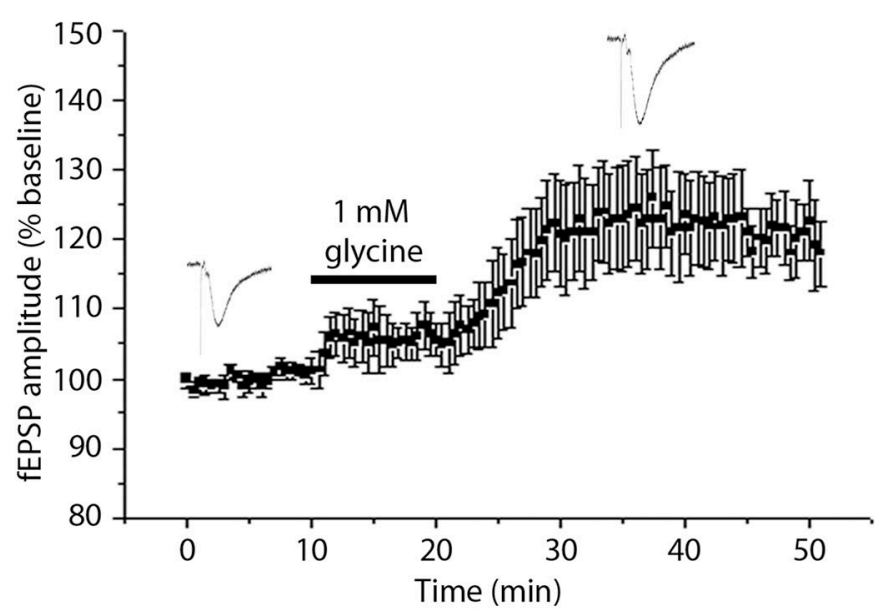

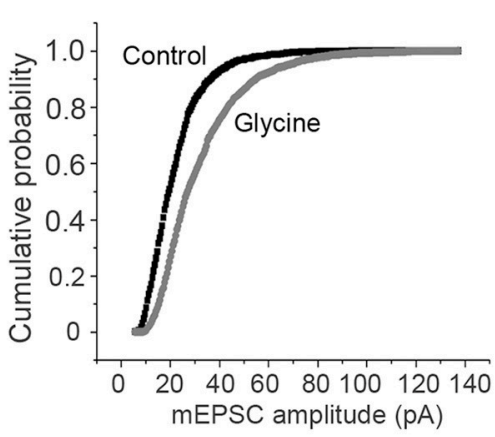

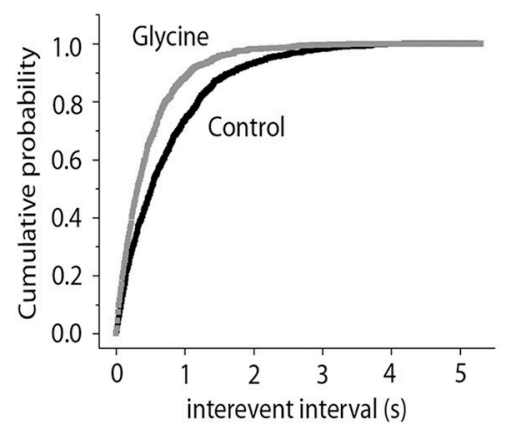

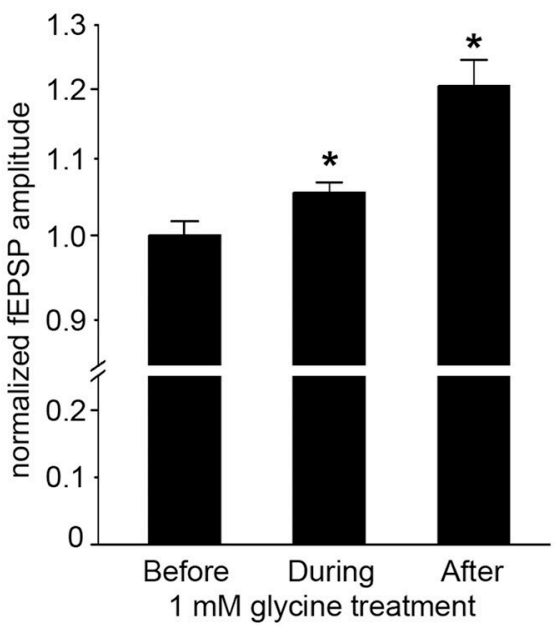

FIGURE 2 | Glycine enhances AMPAR-mediated synaptic currents independent of NMDAR channel activity. (A) Representative AMPAR-mediated mEPSCs recorded before and $10 \mathrm{~min}$ after treatment of glycine $(100 \mu \mathrm{M})$ in hippocampal neurons where NMDARs and glycine receptors are inhibited. (B) Summarized data showing that mean amplitude of AMPAR mEPSCs is significantly increased after $100 \mu \mathrm{M}$ glycine treatment $\left(n=8,{ }^{*} p<0.05\right)$ and that the mean frequency of AMPAR mEPSCs is also increased after glycine treatment $\left(n=8,{ }^{*} p<0.05\right)$. (C) Left: sample of averaged AMPAR mEPSCs from the neurons before (995 events) and after (1407 events) treatment of $100 \mu \mathrm{M}$ glycine. Middle and Right: cumulative probability plots of peak amplitudes and interevent intervals of AMPAR mEPSCs (bin size 0.5 pA and $10 \mathrm{~ms}$, respectively). The mEPSCs amplitude distribution significantly shifts toward greater values after treatment of $100 \mu \mathrm{M} \mathrm{glycine} \mathrm{(p<0.05).} \mathrm{(D)} \mathrm{Left:}$ averaged amplitudes of AMPAR-mediated fEPSP in hippocampal slices recorded before, during and after $1.0 \mathrm{mM}$ glycine treatment $(n=12)$. NMDARs and glycine receptors in the slices are inhibited before recording. Right: summarized data showing that glycine $(1.0 \mathrm{mM})$ increases the amplitudes of AMPAR-mediated fEPSP in hippocampal slices independent of NMDAR channel activity and glycine receptor activation $\left(n=12,{ }^{*} p<0.05\right.$ vs. Before).

of GluN1 + GluN2A (Figure 5B) and cDNAs of GluN1 + GluN2A + GluN2B (Figure 5C), but not in cells transfected with cDNAs of GluN1 + GluN2B (Figure 5D). We also showed that glycine did not increase ERK1/2 phosphorylation in HEK293 cells transfected with cDNAs of GluN1, GluN2A or GluN2B, respectively (Figure 5E). Thus, glycine preferentially 
A

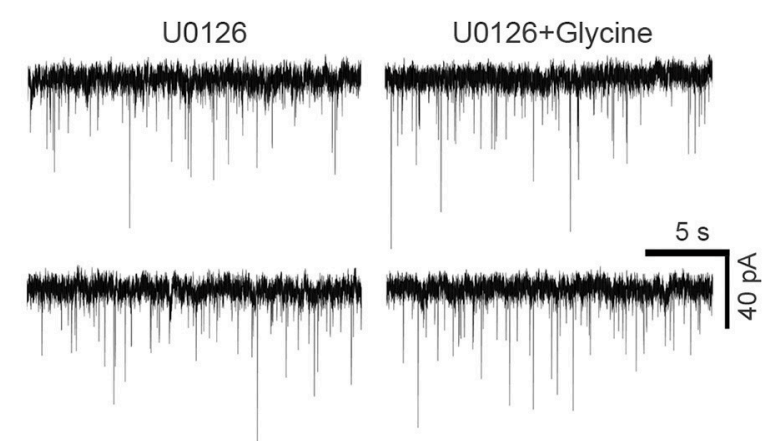

B

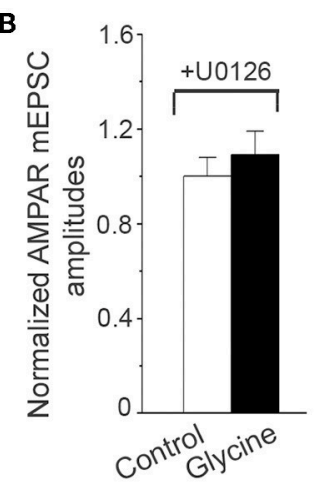

C

Averaged AMPAR mEPSC

U0126 U0126+Glycine

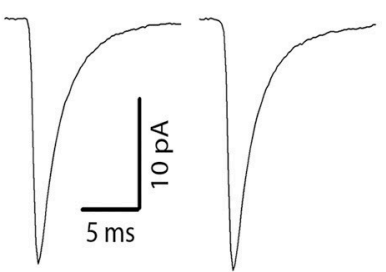

D
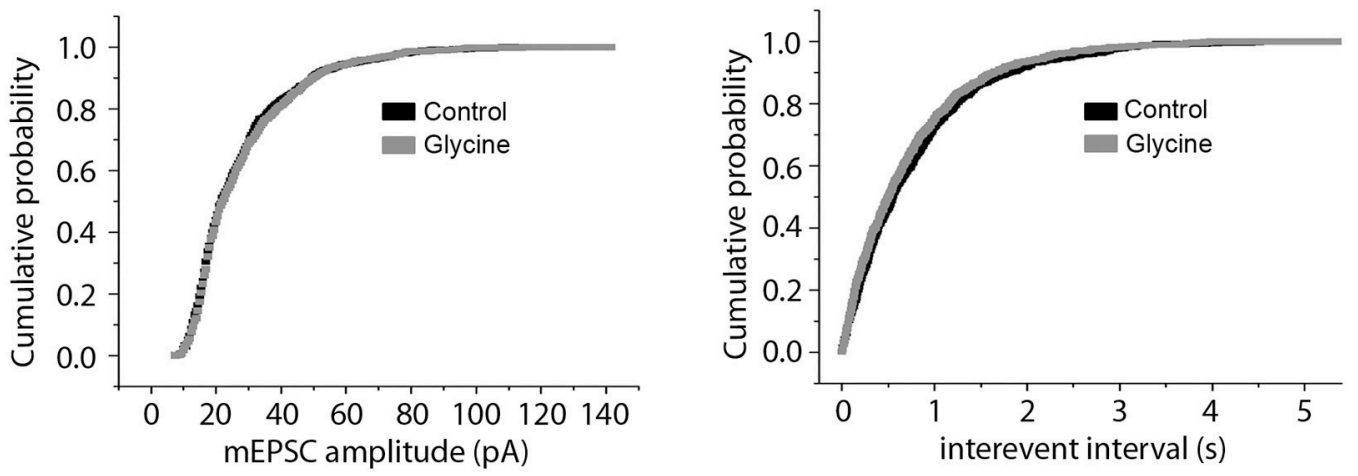

E
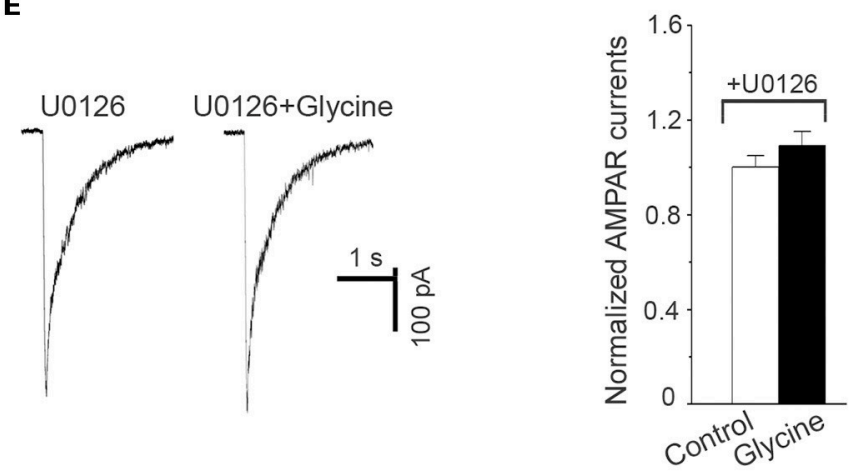

FIGURE 3 | Inhibition of ERK1/2 activation prevents potentiation of AMPAR function by glycine. (A) Representative AMPAR mEPSCs recorded before and $10 \mathrm{~min}$ after $1.0 \mathrm{~min}$ application of $100 \mu \mathrm{M}$ glycine in cultured hippocampal neurons in which NMDARs and glycine receptors are inhibited. (B) Summarized data show that the enhancement of AMPAR mEPSCs by glycine is antagonized by pretreatment of ERK1/2 inhibitor U0126 (5.0 $\mu$ M; $n=6)$. (C) Sample of averaged AMPAR mEPSCs from the neurons at present of U0126 before (881 events) and after (877 events) treatment of $100 \mu \mathrm{M}$ glycine. (D) Cumulative probability plots of peak amplitudes and interevent intervals of AMPAR mEPSCs (bin size $0.5 \mathrm{pA}$ and $10 \mathrm{~ms}$, respectively). (E) Left: Representative AMPAR whole-cell currents induced by AMPA $(100 \mu \mathrm{M})$ recorded before and $10 \mathrm{~min}$ after treatment of $100 \mu \mathrm{M}$ glycine in hippocampal neurons where NMDARs and glycine receptors are inhibited. Right:

Summarized data show that the enhancement of AMPAR whole-cell currents by glycine was blocked by U0126 pretreatment $(n=8)$.

acted on GluN2ARs but not GluN2BRs to enhance ERK1/2 phosphorylation independent of the channel activity of GluN2ARs, indicating that a metabotropic activity of GluN2ARs mediates glycine elevation of ERK1/2 phosphorylation. These data indicate that GluN2A but not GluN2B is required for synaptic metabotropic NMDARs to mediate the glycine effect.

N598 is a critical residue at the selectivity filter of NMDAR channel that determines calcium permeability and GluN1 mutant N598Q has been shown to reduce calcium permeability (Burnashev et al., 1992). We transfected cDNAs of GluN2A with GluN1 mutant N598Q in HEK293 cells, and showed that at $30 \mathrm{~min}$ after $1.0 \mathrm{~min}$ treatment of glycine $(100 \mu \mathrm{M})$ ERK1/2 phosphorylation in cells co-transfected with GluN2A and GluN1(N598Q) was increased (Figure 5F). These results provide molecular evidence to support the conclusion that GluN2AR-mediated ERK1/2 activation is independent of $\mathrm{Ca}^{2+}$ influx. 


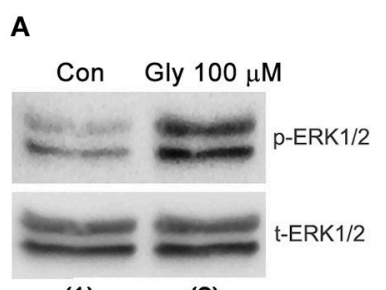

(1)

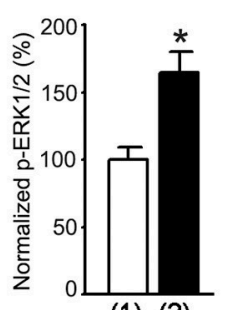

\section{B}

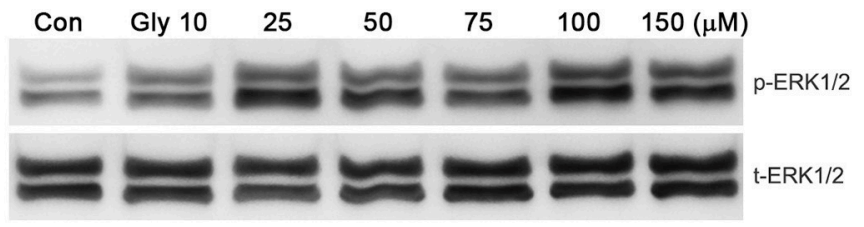

(1) (2)

C

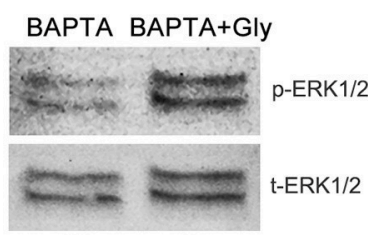

(1)

(2)

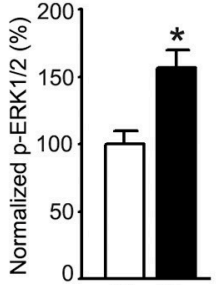

(1) (2)
D

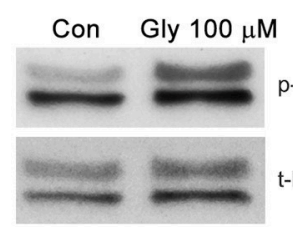

(1)

(2)

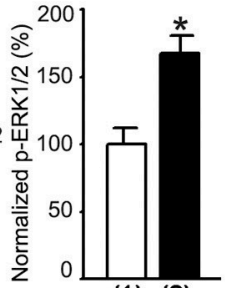

(1) (2)

FIGURE 4 | Glycine increases ERK1/2 phosphorylation independent of NMDAR channel activity in hippocampal neurons. (A) Glycine (100 $\mu$ M) increases p-ERK1/2 after NMDARs and glycine receptors are inhibited $\left(n=8,{ }^{*} p<0.05\right)$. (B) Glycine-induced increase of ERK1/2 phosphorylation is dose-dependent in hippocampal neurons where NMDARs and glycine receptors are inhibited. (C) BAPTA (5.0 mM) treatment does not influence glycine elevation of ERK1/2 phosphorylation in hippocampal neurons where NMDARs and glycine receptors are inhibited $\left(n=6\right.$, $\left.{ }^{*} p<0.05\right)$. (D) At normal level of extracellular Ca ${ }^{2+}$, glycine (100 $\mu \mathrm{M})$ increases $\mathrm{p}$-ERK1/2 in hippocampal neurons where NMDARs and glycine receptors are inhibited $\left(n=6,{ }^{*} p<0.05\right)$. Con: Control; Gly: glycine.

We next applied a knockdown approach to validate the role of metabotropic GluN2ARs in mediating glycine enhancement of ERK1/2 activation in cultured hippocampal neurons. The GluN2A protein expression was suppressed in neurons transducted with GluN2A shRNA lentiviral particles (Figure 6A). The NMDAR channel inactivation procedure was used to block NMDAR channels. As expected, ERK1/2 phosphorylation was increased in neurons treated with the shRNA control at $30 \mathrm{~min}$ after $1.0 \mathrm{~min}$ treatment of glycine $(100 \mu \mathrm{M})$ (Figure 6B), but the effect of glycine was significantly reduced in neurons treated with GluN2A shRNA (Figure 6B). In contrast, glycine increased ERK1/2 phosphorylation in neurons where GluN2B expression was suppressed by GluN2B shRNA treatment (Figures 6C,D).

\section{A Metabotropic Activity of GluN2ARs Mediates Glycine-Induced Potentiation of AMPAR Function}

We thus far showed that glycine-induced potentiation of AMPAR function required ERK1/2 activation in a NMDAR channel activity-independent manner, and that a metabotropic activity of GluN2ARs mediated the elevation of ERK1/2 phosphorylation by glycine. These results support a possibility that a metabotropic GluN2AR mediates the potentiation of AMPAR function by glycine. To test this, we first measured the effect of glycine on AMPA-induced whole-cell currents in neurons treated with GFP + GluN2A shRNA. In contrast to neurons treated with GFP+shRNA control (Figure 7A) or GFP+GluN2B shRNA (Figure 7B), neurons treated with GFP + GluN2A shRNA exhibited no significant increase of AMPAR currents at $30 \mathrm{~min}$ following $1.0 \mathrm{~min}$ treatment of glycine $(100 \mu \mathrm{M})$ (Figure 7C).
We then showed that glycine-induced increase of the amplitude and frequency of AMPAR mEPSCs was blocked by GluN2A shRNA transfection (Figure 7D). These data suggest that glycine activates metabotropic GluN2ARs to enhance AMPAR function.

\section{DISCUSSION}

Recent evidence indicates that NMDAR has a metabotropic property (Vissel et al., 2001; Kessels et al., 2013; Nabavi et al., 2013; Tamburri et al., 2013; Birnbaum et al., 2015; Stein et al., 2015; Weilinger et al., 2016). In this study, under the experimental conditions where the inactivation of NMDARs by $\mathrm{Ca}^{2+}$-free ECS containing MK-801 or by endogenous $\mathrm{Mg}^{2+}$, we demonstrate that glycine, through acting on GluN2ARs, increases AMPAR-mediated synaptic function without depending on the channel activity of GluN2ARs. In the same experimental conditions, we show that ERK1/2 is downstream of GluN2ARs to mediate glycine-induced potentiation of AMPAR function. Thus, we identify a metabotropic function of GluN2ARs. It has been recently shown that GluN2BR has a metabotropic activity that is required for $\beta$-amyloid-induced synaptic depression and sufficient to induce LTD (Nabavi et al., 2013; Tamburri et al., 2013). Together, these findings support the conclusion that both GluN2ARs and GluN2BRs have metabotropic property.

As a co-agonist of NMDARs, glycine is known to not modulate the ionotropic function of AMPARs and/or kainite receptors (Johnson and Ascher, 1987). In this study we demonstrate that after NMDAR channel activity is suppressed, glycine potentates AMPAR currents with a threshold concentration of $25 \mu \mathrm{M}$ (Figure 1B), which is above the concentration required for the ionotropic activation of NMDARs (Johnson and Ascher, 


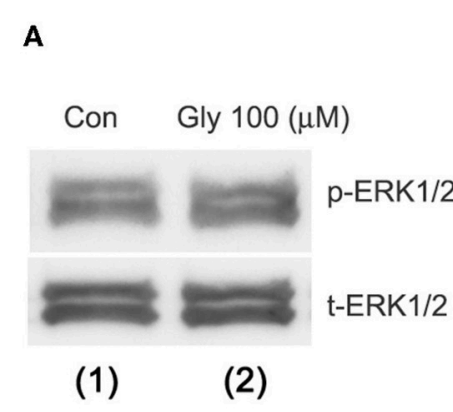

C

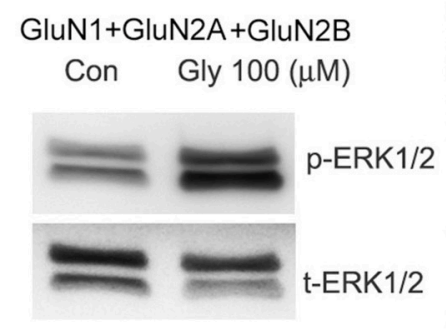

(1)

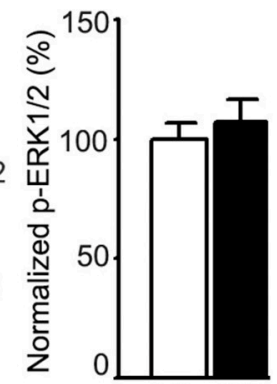

(1) (2)
B

GluN1+GluN2A

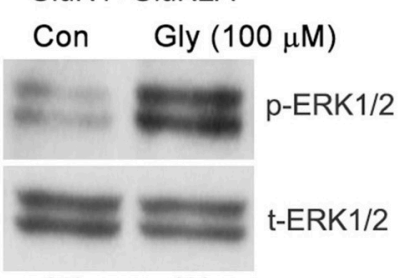

(1)

(2)

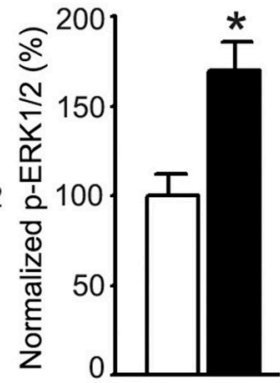

(1) (2)
E

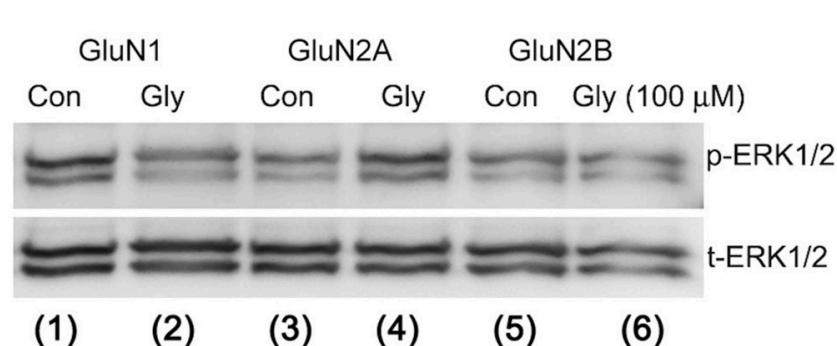

(1)
(2)

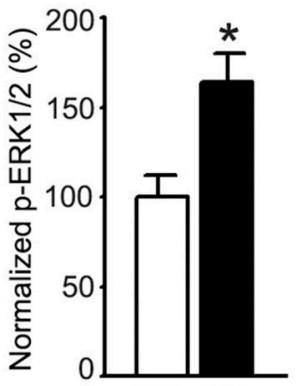

(1) (2)
D

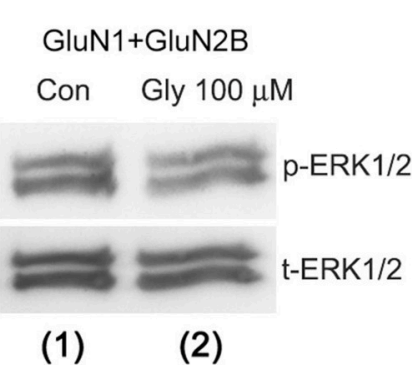

(2)

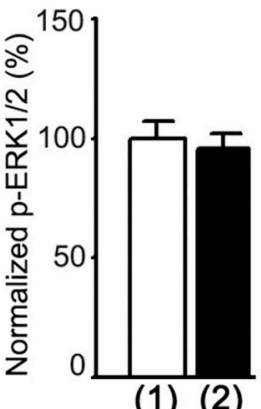

F

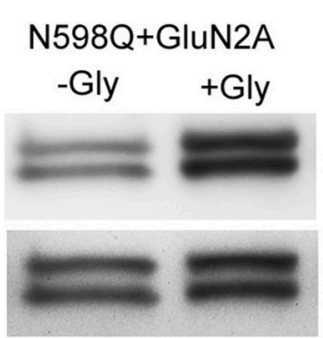

(1)

(2)
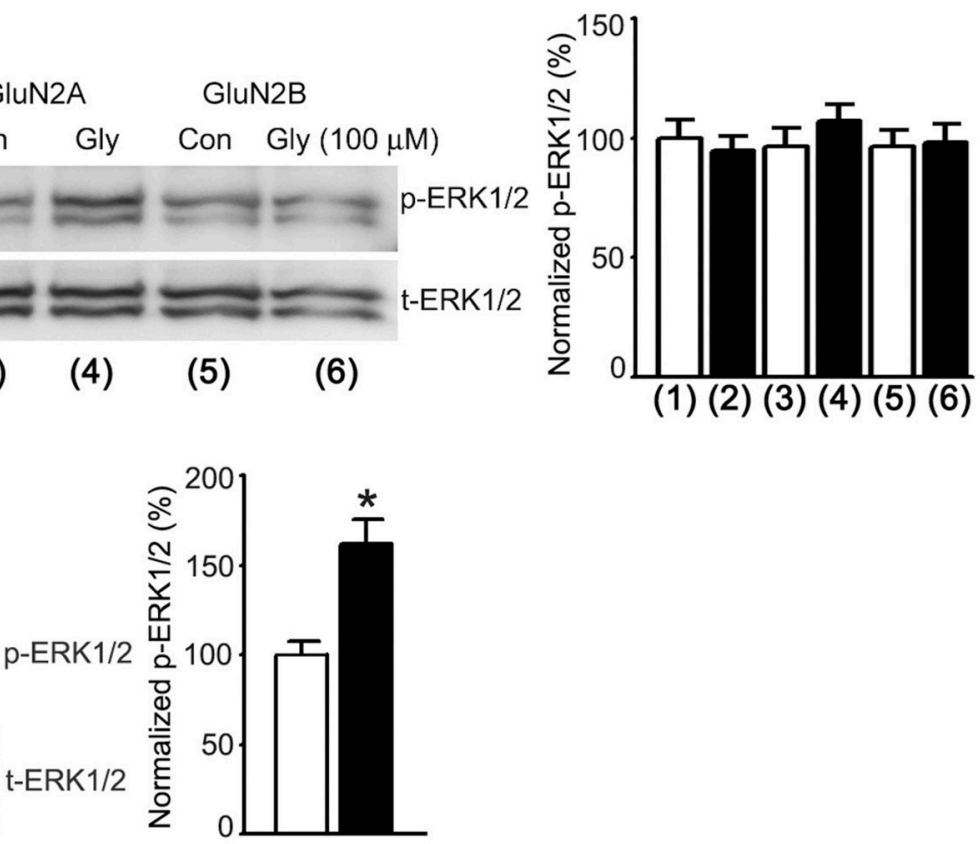

FIGURE 5 | Glycine increases ERK1/2 phosphorylation through metabotropic activity of GluN2ARs in HEK293 cells. (A) The levels of ERK1/2 phosphorylation are not altered by glycine $(100 \mu \mathrm{M})$ treatment in non-transfected HEK293 cells where NMDARs and glycine receptors are inhibited ( $n=6)$. (B) In HEK293 cells transfected with GluN1+GluN2A cDNAs, the ERK1/2 phosphorylation is increased by glycine (100 $\mu$ M) treatment after NMDARs and glycine receptors are inhibited ( $\left.n=6,{ }^{*} p<0.05\right)$. (C) In HEK293 cells transfected with GluN1 + GluN2A + GluN2B cDNAs, the ERK1/2 phosphorylation is increased by glycine (100 $\mu \mathrm{M})$ treatment after NMDARs and glycine receptors are inhibited ( $\left.n=6,{ }^{*} p<0.05\right)$. (D) In HEK293 cells transfected with GluN1 + GluN2B cDNAs, the levels of ERK1/2 phosphorylation are not altered by glycine $(100 \mu \mathrm{M})$ treatment after NMDARs and glycine receptors are inhibited $(n=6)$. (E) In HEK293 cells transfected with cDNAs of GluN1, GluN2A or GluN2B, respectively, the levels of ERK1/2 phosphorylation are not altered by glycine (100 $\mu$ M) treatment after NMDARs and glycine receptors are inhibited $(n=6)$. (F) In HEK293 cells transfected with GluN1(N598Q) + GluN2A, glycine enhances Erk phosphorylation ( $n=6$, ${ }^{*}<$ 0.05 vs. -Gly). Con: Control; Gly: glycine. 
A

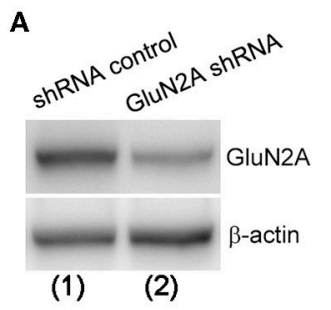

c

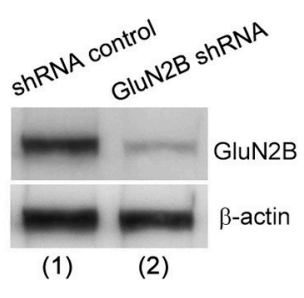

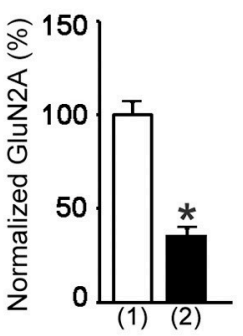

B

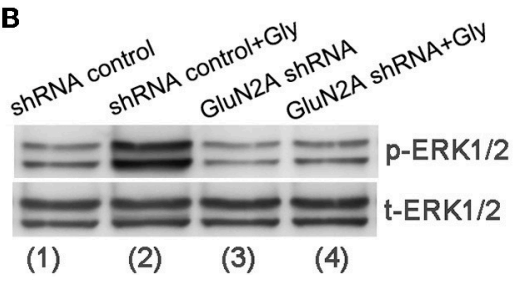

(1)

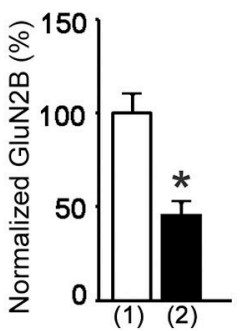

D

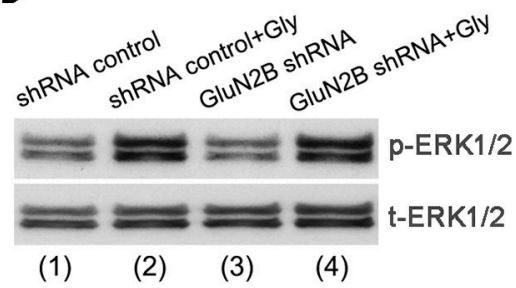

FIGURE 6 | Glycine increases ERK1/2 phosphorylation via metabotropic activity of GluN2ARs in hippocampal neurons. (A) The GluN2A protein expression in cultured mouse hippocampal neurons is suppressed by GluN2A shRNA lentiviral particles ( $n=5$, ${ }^{*} p<0.05$ ). (B) GluN2A knockdown by GluN2A shRNA blocks glycine-induced increase of $p$-ERK1/2 in neurons where NMDARs and glycine receptors are inhibited ( $n=5$, * $p<0.05$ vs. shRNA control). (C) The GluN2B protein expression in mouse hippocampal neurons is suppressed by GluN2B shRNA lentiviral particles ( $n=5$, $\left.{ }^{*} p<0.05\right)$. (D) GluN2B knockdown by GluN2B shRNA does not block glycine increase of $p$-ERK1/2 in neurons where NMDARs and glycine receptors are inhibited $\left(n=5\right.$, ${ }^{*} p<0.05$ vs. shRNA control; $\# p<0.05$ vs. GluN2B shRNA). Gly: glycine.

1987). As GluN2ARs have lower affinity for glycine than GluN2BRs (Dingledine et al., 1999), it is not unreasonable that glycine preferentially acts on metabotropic GluN2AsR but not GluN2BRs to modulate AMPAR currents. These data suggest a possibility that a new binding site other than the classic glycine binding site may mediate the effect of glycine on the metabotropic GluN2ARs. Future study is required to address the issues.

The physiological relevance of glycine in activating metabotropic GluN2ARs remains unclear. Since AMPAR plays a critical role in synaptic plasticity, the observed upregulation of AMPARs by the glycine activation of metabotropic GluN2ARs suggests a possible relevance of glycine/metabotropic GluN2ARs in regulating synaptic transmission. In addition, glycine is increased in response to ischemia-reperfusion injury (Globus et al., 1991; Lo et al., 1998). Glycine may act through metabotropic GluN2ARs to exert its effect in ischemia injury. As the concentration of glycine to activate metabotropic GluN2ARs is higher than that of ionotropic NMDARs, the metabotropic effect of glycine on GluN2ARs might occur when glycine production and release are increased. Serine is known to be an endogenous ligand to bind glycine-binding site of NMDA receptors. It is likely that $\mathrm{D}$-serine may play a similar role to glycine in triggering the metabotropic activity of GluN2ARs. But a higher concentration of D-serine may be required for the effect (Lo et al., 1998).

Our data indicate that while glycine enhances postsynaptic AMPAR function in a NMDAR channel activity-independent manner, a presynaptic modification is also induced by glycine.
The underlying mechanism for this presynaptic modification needs further investigation. However, based on our observation that knockdown of GluN2A prevents glycine-induced increase of AMPAR mEPSC frequency, we reason that the presynaptic modification may be mediated through the metabotropic GluN2ARs at presynaptic terminals (Berretta and Jones, 1996; McGuinness et al., 2010; Buchanan et al., 2012).

GluN2ARs and GluN2BRs are shown to play different roles in regulating neuronal survival/death and synaptic plasticity (Liu et al., 2004, 2007; Chen et al., 2008). The mechanisms underlying the differential effects of these NMDAR subtypes have been elusive. Our study reveals that a metabotropic activity of GluN2ARs regulates AMPAR function at synaptic sites. This observation provides a mechanism that may explain in part why GluN2AR plays a different role than GluN2BR in synaptic plasticity.

It is not clear how glycine binds to metabotropic GluN2ARs to activate ERK1/2. One of the possibilities is that a structural rearrangement of GluN1 and/or GluN2A but not GluN2B upon glycine binding may directly or indirectly lead to the activation of ERK1/2-dependent signaling. The ERK1/2 signaling is known to be activated by NMDARs and plays an important role in synaptic plasticity (Sweatt, 2004; Thomas and Huganir, 2004). NMDAR-dependent ERK1/2 activation involves the small GTPase Ras, which is stimulated by specific nucleotide exchange factors (GEFs) (Thomas and Huganir, 2004). It has been shown that GluN2ARs and GluN2BRs have antagonistic actions on Ras-ERK1/2 activation (Kim R. H. et al., 2005). GluN2ARs promote, whereas GluN2BRs 
A

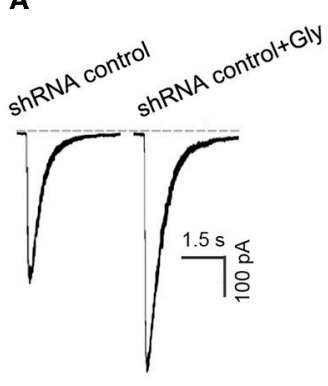

C

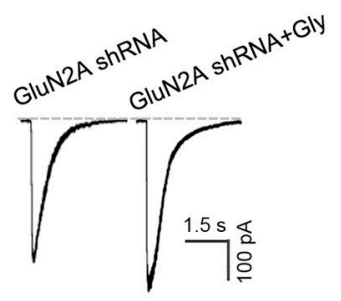

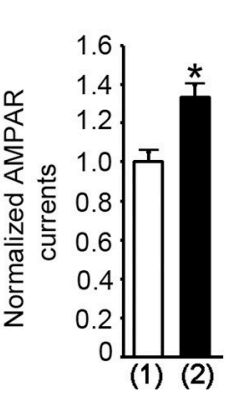

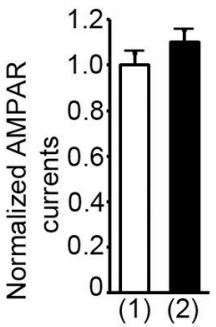

B

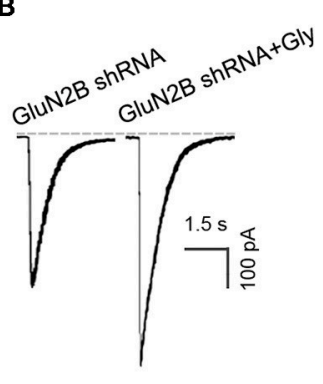

D

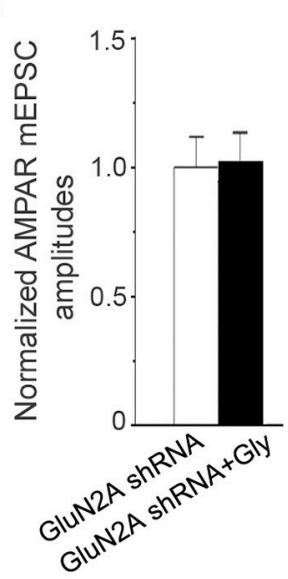

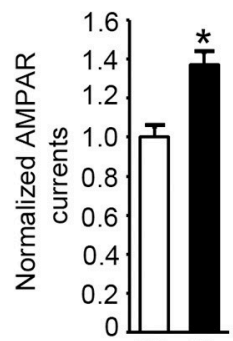

(1) (2)

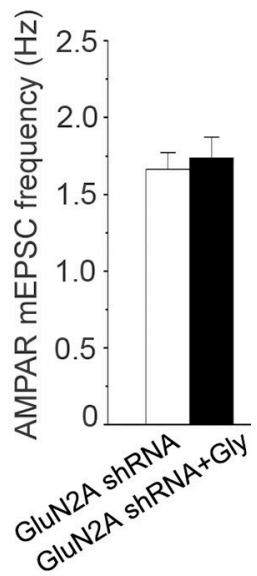

FIGURE 7 | Glycine enhances AMPAR function through metabotropic activity of GluN2ARs in hippocampal neurons. (A) Transfection of shRNA control does not influence glycine-induced potentiation of AMPAR currents in hippocampal neurons after NMDARs and glycine receptors are inhibited $\left(n=7,{ }^{\star} p<0.05\right)$. (1) shRNA control; (2) shRNA control + Gly. (B) GluN2B knockdown by GluN2B shRNA transfection does not influence glycine (100 $\mu$ M) potentiation of AMPA-induced whole-cell currents in neurons where NMDARs and glycine receptors are inhibited ( $n=7, p<0.05)$. (1) GluN2B shRNA; (2) GluN2B shRNA + Glycine. (C)

Knockdown of GluN2A by GluN2A shRNA transfection blocks glycine-induced potentiation of AMPAR currents in hippocampal neurons after NMDARs and glycine receptors are inhibited ( $n=7$ ). (1) GluN2A shRNA; (2) GluN2A shRNA+Gly. (D) Knockdown of GluN2A by GluN2A shRNA prevents glycine-induced increase in mean amplitude and mean frequency of AMPAR mEPSCs in hippocampal neurons after NMDARs and glycine receptors are inhibited ( $n=6$ for both all groups). Gly: glycine.

inhibit, Ras-ERK1/2 activation (Kim R. H. et al., 2005). Through Ras-GRF2 (a Ras-GEF) and ERK1/2 signaling pathway, GluN2AR induces long-term potentiation (LTP) in CA1 pyramidal neurons of mouse hippocampus (Jin and Feig, 2010). We will determine whether the Ras-GRF2 is involved in metabotropic GluN2AR-mediated enhancement of ERK1/2 activation.

\section{AUTHOR CONTRIBUTIONS}

QW designed the experiments, wrote and edited the manuscript. HF, HM, JC designed the experiments and edited the manuscript. LL, RH, BL, TC, JCC, YN, JZ, and ML performed experiments and the statistical analysis. LL wrote the draft of the manuscript.

\section{REFERENCES}

Aarts, M., Liu, Y., Liu, L., Besshoh, S., Arundine, M., Gurd, J., et al. (2002). Treatment of ischemic brain damage by perturbing NMDA receptor- PSD-95 protein interactions. Science 298, 846-850. doi: 10.1126/science.1072873

\section{ACKNOWLEDGMENTS}

We thank Drs. Gavin Rumbaugh, Jon Johnson, Thomas Kuner for providing us with GluN1, GluN2A, GluN2B, GluNR1(N598Q) cDNAs. We also thank Dr. Peter Seeburg, Thomas Kuner and Robert Renden to review the manuscript. This work was supported by National Center for Research Resources (RR024210) of NIH, National Institute of General Medical Sciences (GM103554) of NIH, National Institute of Neurological Disorders and Stroke of NIH (R21NS077205), American Heart Association (12GRNT9560012), China Key Project of Basic Research (“973” Project; 2014CB541606), Natural Science Foundation of China (NSFC; 81470599) and Collaborative Innovation Center for Brain Science to QW.

Adler, E. M., Augustine, G. J., Duffy, S. N., and Charlton, M. P. (1991). Alien intracellular calcium chelators attenuate neurotransmitter release at the squid giant synapse. J. Neurosci. 11, 1496-1507.

Barria, A., and Malinow, R. (2002). Subunit-specific NMDA receptor trafficking to synapses. Neuron 35, 345-353. doi: 10.1016/S0896-6273(02)00776-6 
Berretta, N., and Jones, R. S. (1996). Tonic facilitation of glutamate release by presynaptic N-methyl-D-aspartate autoreceptors in the entorhinal cortex. Neuroscience 75, 339-344. doi: 10.1016/0306-4522(96)00301-6

Birnbaum, J. H., Bali, J., Rajendran, L., Nitsch, R. M., and Tackenberg, C. (2015). Calcium flux-independent NMDA receptor activity is required for Abeta oligomer-induced synaptic loss. Cell Death Dis. 6:e1791. doi: 10.1038/cddis.2015.160

Brewer, G. J., Torricelli, J. R., Evege, E. K., and Price, P. J. (1993). Optimized survival of hippocampal neurons in B27-supplemented Neurobasal, a new serum-free medium combination. J. Neurosci. Res. 35, 567-576. doi: 10.1002/jnr.490350513

Buchanan, K. A., Blackman, A. V., Moreau, A. W., Elgar, D., Costa, R. P., Lalanne, T. et al. (2012). Target-specific expression of presynaptic NMDA receptors in neocortical microcircuits. Neuron 75, 451-466. doi: 10.1016/j.neuron.2012.06.017

Burnashev, N., Schoepfer, R., Monyer, H., Ruppersberg, J., P., Günther, W., Sakmann, B. et al. (1992). Control by asparagine residues of calcium permeability and magnesium blockade in the NMDA receptor. Science 257, 1415-1419. doi: 10.1126/science.1382314

Chen, M., Lu, T. J., Chen, X. J., Zhou, Y., Chen, Q., Feng, X. Y. et al. (2008). Differential roles of NMDA receptor subtypes in ischemic neuronal cell death and ischemic tolerance. Stroke 39, 3042-3048. doi: 10.1161/STROKEAHA.108.521898

Choi, D. W. (1988). Glutamate neurotoxicity and diseases of the nervous system. Neuron 1, 623-634. doi: 10.1016/0896-6273(88)90162-6

Collingridge, G. L., Isaac, J. T., and Wang, Y. T. (2004). Receptor trafficking and synaptic plasticity. Nat. Rev. Neurosci. 5, 952-962. doi: 10.1038/nrn1556

Constantine-Paton, M., Cline, H. T., and Debski, E. (1990). Patterned activity, synaptic convergence, and the NMDA receptor in developing visual pathways. Annu. Rev. Neurosci. 13, 129-154. doi: 10.1146/annurev.ne.13.030190. 001021

Dingledine, R., Borges, K., Bowie, D., and Traynelis, S. F. (1999). Traynelis, The glutamate receptor ion channels. Pharmacol. Rev. 51, 7-61.

Globus, M. Y., Busto, R., Martinez, E., Valdés, I., Dietrich, W. D., and Ginsberg, M. D. (1991). Comparative effect of transient global ischemia on extracellular levels of glutamate, glycine, and gamma-aminobutyric acid in vulnerable and nonvulnerable brain regions in the rat. J. Neurochem. 57, 470-478. doi: 10.1111/j.1471-4159.1991.tb03775.x

Hayashi, T., Thomas, G. M., and Huganir, R. L. (2009). Dual palmitoylation of NR2 subunits regulates NMDA receptor trafficking. Neuron 64, 213-226. doi: 10.1016/j.neuron.2009.08.017

Hotokezaka, H., Sakai, E., Kanaoka, K., Saito, K., Matsuo, K., Kitaura, H., et al. (2002). U0126 and PD98059, specific inhibitors of MEK, accelerate differentiation of RAW264.7 cells into osteoclast-like cells. J. Biol. Chem. 277, 47366-47372. doi: 10.1074/jbc.M208284200

Jin, S. X., and Feig, L. A. (2010). Long-term potentiation in the CA1 hippocampus induced by NR2A subunit-containing NMDA glutamate receptors is mediated by Ras-GRF2/Erk map kinase signaling. PLoS ONE 5:e11732. doi: 10.1371/journal.pone.0011732

Johnson, J. W., and Ascher, P. (1987). Glycine potentiates the NMDA response in cultured mouse brain neurons. Nature 325, 529-531. doi: 10.1038/325 $529 \mathrm{a} 0$

Kerchner, G. A., and Nicoll, R. A. (2008). Silent synapses and the emergence of a postsynaptic mechanism for LTP. Nat. Rev. Neurosci. 9, 813-825. doi: $10.1038 / \mathrm{nrn} 2501$

Kessels, H. W., Nabavi, S., and Malinow, R. (2013). Metabotropic NMDA receptor function is required for beta-amyloid-induced synaptic depression. Proc. Natl. Acad. Sci. U.S.A. 110, 4033-4038. doi: 10.1073/pnas.1219605110

Kim, M. J., Dunah, A., W., Wang, Y. T., and Sheng, M. (2005). Differential roles of NR2A- and NR2B-containing NMDA receptors in Ras-ERK signaling and AMPA receptor trafficking. Neuron 46, 745-760. doi: 10.1016/j.neuron.2005. 04.031

Kim, R. H., Peters, M., Jang, Y., Shi, W., Pintilie, M., Fletcher G. C., et al. (2005). DJ-1, a novel regulator of the tumor suppressor PTEN. Cancer Cell 7, 263-273. doi: 10.1016/j.ccr.2005.02.010

Kuner, T., and Schoepfer, R. (1996). Multiple structural elements determine subunit specificity of Mg2+ block in NMDA receptor channels. J. Neurosci. 16, 3549-3558.
Li, Z., Jo, J., Jia, J. M., Lo, S. C., Whitcomb, D. J., Jiao, S., et al. (2010). Caspase-3 activation via mitochondria is required for long-term depression and AMPA receptor internalization. Cell 141, 859-871. doi: 10.1016/j.cell.2010.03.053

Liu, B., Liao, M., Mielke, J. G., Ning, K., Chen, Y., Li, L., et al. (2006). Ischemic insults direct glutamate receptor subunit 2-lacking AMPA receptors to synaptic sites. J. Neurosci. 26, 5309-5319. doi: 10.1523/JNEUROSCI.0567-06.2006

Liu, L., Wong, T. P., Pozza, M. F., Lingenhoehl, K., Wang, Y., Wang, Y. T., et al. (2004). Role of NMDA receptor subtypes in governing the direction of hippocampal synaptic plasticity. Science 304, 1021-1024. doi: 10.1126/science.1096615

Liu, Y., Wong, T. P., Aarts, M., Rooyakkers, A., Liu, L., Lai, T. W., et al. (2007), NMDA receptor subunits have differential roles in mediating excitotoxic neuronal death both in vitro and in vivo. J. Neurosci. 27, 2846-2857. doi: 10.1523/JNEUROSCI.0116-07.2007

Lo, E. H., Pierce, A. R., Matsumoto, K., Kano, T., Evans, C. J., and Newcomb, R. (1998). Alterations in $\mathrm{K}+$ evoked profiles of neurotransmitter and neuromodulator amino acids after focal ischemia-reperfusion. Neuroscience 83, 449-458. doi: 10.1016/S0306-4522(97)00434-X

Loftis, J. M., and Janowsky, A. (2003). The N-methyl-D-aspartate receptor subunit NR2B: localization, functional properties, regulation, and clinical implications. Pharmacol. Ther. 97, 55-85. doi: 10.1016/S0163-7258(02)00302-9

Lu, W., and Roche, K. W. (2012). Posttranslational regulation of AMPA receptor trafficking and function. Curr. Opin. Neurobiol. 22, 470-479. doi: 10.1016/j. conb.2011.09.008

Lynch, J. W. (2004). Molecular structure and function of the glycine receptor chloride channel. Physiol. Rev. 84, 1051-1095. doi: 10.1152/physrev.00042.2003

MacDonald, J. F., and Nowak, L. M. (1990). Mechanisms of blockade of excitatory amino acid receptor channels. Trends Pharmacol. Sci. 11, 167-172. doi: 10.1016/0165-6147(90)90070-O

Malenka, R. C., and Nicoll, R. A. (1999). Long-term potentiation-a decade of progress? Science 285, 1870-1874. doi: 10.1126/science.285.5435.1870

Malinow, R., and Malenka, R. C. (2002). AMPA receptor trafficking and synaptic plasticity. Ann. Rev. Neurosci. 25, 103-126. doi: 10.1146/annurev.neuro.25.112701.142758

Man, H. Y. (2011). GluA2-lacking, calcium-permeable AMPA receptorsinducers of plasticity? Curr. Opin. Neurobiol. 21, 291-298. doi: 10.1016/j.conb.2011.01.001

McGuinness, L., Taylor, C., Taylor, R. D., Yau, C., Langenhan, T., Hart, M. L., et al. (2010). Presynaptic NMDARs in the hippocampus facilitate transmitter release at theta frequency. Neuron 68, 1109-1127. doi: 10.1016/j.neuron.2010.11.023

Monyer, H., Sprengel, R., Schoepfer, R., Herb, A., Higuchi, M., Lomeli, H., et al. (1992). Seeburg, Heteromeric NMDA receptors: molecular and functional distinction of subtypes. Science 256, 1217-1221. doi: $10.1126 /$ science.256.5060.1217

Nabavi, S., Kessels, H. W., Alfonso, S., Aow, J., Fox, R., and Malinow, R. (2013). Metabotropic NMDA receptor function is required for NMDA receptordependent long-term depression. Proc. Natl. Acad. Sci. U.S.A. 110, 4027-4032. doi: 10.1073/pnas.1219454110

Ning, K., Pei, L., Liao, M., Liu, B., Zhang, Y., Jiang, W., et al. (2004). Dual neuroprotective signaling mediated by downregulating two distinct phosphatase activities of PTEN. J. Neurosci. 24, 4052-4060. doi: 10.1523/JNEUROSCI.5449-03.2004

Rosenmund, C., Clements, J. D., and Westbrook, G. L. (1993). Nonuniform probability of glutamate release at a hippocampal synapse. Science 262, 754-757. doi: 10.1126/science.7901909

Shan, Y., Liu, B., Li, L., Chang, N., Li, L., Wang, H., et al. (2009). Regulation of PINK1 by NR2B-containing NMDA receptors in ischemic neuronal injury. $J$. Neurochem. 111, 1149-1160. doi: 10.1111/j.1471-4159.2009.06398.x

Stein, I. S., Gray, J. A., and Zito, K. (2015). Non-Ionotropic NMDA Receptor Signaling Drives Activity-Induced Dendritic Spine Shrinkage. J. Neurosci. 35, 12303-12308. doi: 10.1523/JNEUROSCI.4289-14.2015

Sweatt, J. D. (2004). Mitogen-activated protein kinases in synaptic plasticity and memory. Curr. Opin. Neurobiol. 14, 311 doi: 10.1016/j.conb.2004.04.001

Tamburri, A., Dudilot, A., Licea, S., Bourgeois, C., and Boehm, J. (2013). NMDAreceptor activation but not ion flux is required for amyloid-beta induced synaptic depression. PLoS ONE 8:e65350. doi: 10.1371/journal.pone.0065350

Thomas, G. M., and Huganir, R. L. (2004). MAPK cascade signalling and synaptic plasticity. Nat. Rev. Neurosci. 5, 173-183. doi: 10.1038/nrn1346 
Tu, W., Xu, X., Peng, L., Zhong, X., Zhang, W., Soundarapandian, M., et al. (2010). DAPK1 interaction with NMDA receptor NR2B subunits mediates brain damage in stroke. Cell 140, 222-234. doi: 10.1016/j.cell.2009.12.055

Vissel, B., Krupp, J. J., Heinemann, S. F., and Westbrook, G. L. (2001). A usedependent tyrosine dephosphorylation of NMDA receptors is independent of ion flux. Nat. Neurosci. 4, 587-596. doi: 10.1038/88404

Wan, Q., Xiong, Z. G., Man, H. Y., Ackerley, C. A., Braunton, J., Lu, W. Y., et al. (1997). Recruitment of functional GABA(A) receptors to postsynaptic domains by insulin. Nature 388, 686-690. doi: 10.1038/41792

Weilinger, N. L., Lohman, A. W., Rakai, B. D., Ma, E. M., Bialecki, J., Thompson, R. J., et al. (2016). Metabotropic NMDA receptor signaling couples Src family kinases to pannexin-1 during excitotoxicity. Nat. Neurosci. 19, 432-442. doi: $10.1038 / \mathrm{nn} .4236$

Wu, C. P., Cheung, G., Rakhshani, N., Parvardeh, S., Asl, M. N., Zhang, L., et al. (2005). Ca3 neuronal activities of dorsal and ventral hippocampus are differentially altered in rats after prolonged post-ischemic survival. Neuroscience 130, 527-539. doi: 10.1016/j.neuroscience.2004.09.041

Conflict of Interest Statement: The authors declare that the research was conducted in the absence of any commercial or financial relationships that could be construed as a potential conflict of interest.

Copyright (c) $2016 \mathrm{Li}, \mathrm{Hu}$, Lujan, Chen, Zhang, Nakano, Cui, Liao, Chen, Man, Feng and Wan. This is an open-access article distributed under the terms of the Creative Commons Attribution License (CC BY). The use, distribution or reproduction in other forums is permitted, provided the original author(s) or licensor are credited and that the original publication in this journal is cited, in accordance with accepted academic practice. No use, distribution or reproduction is permitted which does not comply with these terms. 